Original Article

\title{
FOLIC ACID-CONJUGATED DOXORUBICIN-LOADED PHOTOSENSITIZING MANGANESE FERRITE NANOPARTICLES: SYNTHESIS, CHARACTERIZATION AND ANTICANCER ACTIVITY AGAINST HUMAN CERVICAL CARCINOMA CELL LINE (HELA)
}

\author{
MUHAMMAD HASSAN SAFDAR', HUMNA HASAN1, MARIAM ANEES¹, ZAHID HUSSAIN2*
}

1Department of Biochemistry, Faculty of Biological Sciences, Quaid-i-Azam University, Islamabad 45320, Punjab, Pakistan, ${ }^{2}$ Department of Pharmaceutics, Faculty of Pharmacy, Universiti Teknologi MARA, Puncak Alam Campus, Bandar Puncak Alam 42300, Selangor, Malaysia Email: zahidh85@yahoo.com

Received: 23 Jan 2017 Revised and Accepted: 09 Mar 2017

\section{ABSTRACT}

Objective: On account of several complications and adverse effects associated with the use of conventional chemotherapeutic regimen, the advanced drug-targeted therapies have gained the remarkable attention of the researchers due to their fabulous pharmaceutical and therapeutic advantages. The present study was designed with the aim to synthesize manganese ferrite nanoparticles $\left(\mathrm{MnFe}_{2} \mathrm{O}_{4} \mathrm{NPs}\right)$ and folic acid-conjugated doxorubicin (DOX)-loaded manganese ferrite bovine serum albumin NPs (FA-BSA-DOX-MnFe $\mathrm{O}_{4} \mathrm{NPs}$ ) using desolvation cross-linking method.

Methods: Having assessed their physicochemical characteristics, the prepared NPs were evaluated for hem compatibility, photo-mediated cytotoxicity, and anti-cancer potential against human cervical carcinoma cell line (HeLa) using a range of in vitro assays which include hemolysis assay, sulforhodamine B (SRB) and MTT assays.

Results: Spectroscopic characterization revealed that $\mathrm{MnFe}_{2} \mathrm{O}_{4} \mathrm{NPs}$ were spherical with an average size diameter of approx. $15 \mathrm{~nm}$ and a band gap of $1.4 \mathrm{eV}$. Another remarkable feature of FA-BSA-DOX conjugated $\mathrm{MnFe}_{2} \mathrm{O}_{4} \mathrm{NPs}$ was high entrapment efficiency (approx. 95\%). MTT assay demonstrated that $\mathrm{MnFe}_{2} \mathrm{O}_{4} \mathrm{NPs}$ revealed potential photosensitizing ability upon exposure to sunlight. FA-BSA-DOX conjugated $\mathrm{MnFe}_{2} \mathrm{O}_{4} \mathrm{NPs}$ showed promising cytotoxicity against human cervical epithelial malignant carcinoma cell line (HeLa). Interestingly, the cytotoxicity of these NPs was gradually increased with time of exposure to sunlight.

Conclusion: These findings suggested that FA-BSA-DOX conjugated $\mathrm{MnFe}_{2} \mathrm{O}_{4} \mathrm{NPs}$ exhibit promising photosensitizing and anticancer potential against human cervical carcinoma and thus can be considered as an alternative targeted therapy against human cervical cancer.

Keywords: Cervical carcinoma, Doxorubicin, Folic acid, Manganese ferrite nanoparticles, Photodynamic therapy, Anti-cancer activity

(C) 2017 The Authors. Published by Innovare Academic Sciences Pvt Ltd. This is an open access article under the CC BY license (http://creativecommons.org/licenses/by/4.0/) DOI: http://dx.doi.org/10.22159/ijpps.2017v9i5.17261

\section{INTRODUCTION}

Cancer tends to remain the major cause of fatalities worldwide. For decades, scientists have been hoping to find a promising cure for the said menace. Current clinical therapy for cancer includes chemotherapy, surgery, radiotherapy, and less commonly gene therapy and hyperthermia (HT), amongst others. However, various associated side effects undermine their use, for example, cardio toxicity and myelosuppression in chemotherapy; alongside infection, bleeding, or irritation in radiotherapy and surgery, respectively [1].

The use of nanotechnology-based targeted therapies has gained the remarkable attention of the researchers in recent years, especially on account of the side effects associated with the conventional therapeutic regimen [2]. The prime objectives of research of nanobiotechnologies in drug delivery include reduced toxicity, specific drug targeting and delivery, elevated safety and biocompatibility [1]. The recent leap is the combined onco-therapeutic technique which is employed for targeting cancers through multiple mechanisms, for instance, a combination of targeted drug delivery and photodynamic therapy (PDT). Specifically, this strategy tends to target various prime signal transduction pathways for the amplification of fused therapeutic efficacy [3]. This combination may also give rise to synergistic effects thereby, leading to a reduction of the dose of the drug for enhanced feasibility, thereby undermining side effects usually associated with chemotherapeutic agents like doxorubicin (DOX) [4].

The progressing possibilities have given rise to the employment of light-elicited release of chemotherapeutics from photo-responsive nanoparticles (NPs); bearing the capacity to eradicate malignant cells by drawing in external electromagnetic energy [3]. Therefore, the light and chemotherapeutic agent combination is a preeminently stimulating methodology focusing on optimised cancer treatment.
This light-mediated drug release may be combined with the photodynamic modes, whereby increased cancer cell killing may be ensured through combination or synergistic therapy [5].

Folate receptor is a glycosyl-phosphatidyl-inositol (GPI)-linked membrane glycoprotein which exhibits limited expression on the normal cells but is over-expressed on large numbers of cancer cells. Cells develop a high-affinity FR to internalise folate or even folateconjugates, which is referred to as receptor-mediated endocytosis. Thus, folate has extensively been employed as a targeting ligand in various drug delivery systems.

Super paramagnetic iron oxide NPs extend attractive possibilities for the amelioration of site-specific drug delivery, on account of their transportation to targeted areas by an external magnetic field. Furthermore, they have also been used for the enhancement of magnetic resonance imaging contrast in cancer detection [6]. One such reported super paramagnetic NP, manganese ferrite is a potential candidate contrast agent for magnetic resonance imaging because of a high magnetisation due to large magnetic spin [7].

This research was focused on the synthesis of biocompatible magnetic $\mathrm{MnFe}_{2} \mathrm{O}_{4} \mathrm{NPs}$ as potential photosensitizing agents; alongside the formation of folic acid-conjugated DOX-loaded manganese ferrite bovine serum albumin NPs (FA-BSA-DOX $\mathrm{MnFe}_{2} \mathrm{O}_{4} \mathrm{NPs}$ ) for cumulative drug delivery and investigation of in vitro anticancer potential against human cervical epithelial malignant carcinoma (HeLa) cells.

\section{MATERIALS AND METHODS}

\section{Materials}

Manganese (III) acetylacetonate, iron (III) acetylacetonate (97\%), 
1,2-hexadecanediol (90\%), oleylamine (98\%), oleic acid (99\%), isopropanol (99.7\%),folic acid (97\%), doxorubicin hydrochloride (98.0\%), bovine serum albumin(Mw 66,000), glutaraldehyde, $\mathrm{N}$ hydroxysuccinimide (NHS, 98\%), 1-ethyl-3-(3-dimethylaminopropyl) carbodiimide hydrochloride (EDAC), citric acid were purchased from Sigma-Aldrich (USA); methylene blue from Merck and co. All other chemicals were analytical grade and used directly.

\section{Synthesis of $\mathrm{MnFe}_{2} \mathrm{O}_{4} \mathrm{NPs}$}

$\mathrm{MnFe}_{2} \mathrm{O}_{4}$ NPs were fabricated by thermal decomposition method using iron (III) acetylacetonate $\left[\mathrm{Fe}(\mathrm{acac})_{3}\right]$ and manganese (III) acetylacetonate $\left[\mathrm{Mn}(\mathrm{acac})_{2}\right]$ as starting materials. A mixture containing $2 \mathrm{mmol}$ of $\mathrm{Fe}(\mathrm{acac})_{3}, 1 \mathrm{mmol}$ of $\mathrm{Mn}(\mathrm{acac})_{2}, 10 \mathrm{mmol}$ of 1,2-hexadecandiol, $3 \mathrm{ml}$ of oleylamine, $2 \mathrm{ml}$ of oleic acid, and $15 \mathrm{ml}$ of 1-octadecene was magnetically stirred and heated to $200^{\circ} \mathrm{C}$ for 45 min under a blanket of argon. The solution was further heated to reflux at 280 for $30 \mathrm{~min}$ before it was cooled down to room temperature. The products were precipitated by adding isopropanol $(45 \mathrm{ml})$ and then were collected by centrifugation $(8000 \mathrm{rpm})$ for 10 min and redispersed in hexane until further use.

Ligand-exchange using citric acid was performed following the procedure described previously [8], with minor modifications. The hydrophobic $\mathrm{MnFe}_{2} \mathrm{O}_{4}$-oleic acid NPs were dried and dispersed in a $50 / 50$ mixture of 1, 2-dicholorobenzene and N, N'dimethylformamide ( $15 \mathrm{ml}$ of total volume), to which $0.1 \mathrm{~g}$ of citric acid was added. The mixture was incubated in a rotating agitator at $100^{\circ} \mathrm{C}$ for approximately $18 \mathrm{~h}$. Hydrophilic $\mathrm{MnFe}_{2} \mathrm{O}_{4}$-citric acid NPs were precipitated by addition of diethyl ether $(40 \mathrm{ml})$ and recovered by magnetic separation. The particles were re-dispersed in acetone and re-precipitated by means of a magnet three times to remove all traces of free citric acid. Afterwards, the prepared NPs were dried in an oven at $37^{\circ} \mathrm{C}$ and stored for further use.

\section{Physicochemical characterization}

The characterizations of $\mathrm{MnFe}_{2} \mathrm{O}_{4} \mathrm{NPs}$ were carried out using U. $\mathrm{V} /$ visible spectroscopy, $\mathrm{x}$-ray diffraction (XRD), and diffuse reflectance spectroscopy (DRS). U. V/visible spectroscopy was performed using a quartz cuvette with a path length of $1 \mathrm{~cm}$ of the instrument (LAMBDA ${ }^{\mathrm{TM}} 25 \mathrm{UV} / \mathrm{Vis} /$ near infrared (Perkin Elmer, Waltham, USA) at room temperature.

XRD was conducted using a D8 advance XRD (Bruker Corporation, Billerica, USA) bearing $\mathrm{CuK} \alpha$ radiations $\left(\lambda=1.54056 \mathrm{~A}^{\circ}\right)$ at energy of $45 \mathrm{kV}$.

Optical properties (percentage reflectance) of the prepared sample were studied by diffuse reflectance spectroscopy (DRS) (Perkin Elmer UV/Vis/NIR spectrometer-lambda 950). The reflectance spectra were taken at room temperature within the range of 200$800 \mathrm{~nm}$.

The optical band gap energies of all synthesized samples were estimated using the DRS technique. Band gap energies of all synthezised samples were calculated by Kubelka-Munk function following previously reported procedure [9]. The Kubelka-Munk function is expressed as follows:

$$
F(R)=\frac{(1-R)^{2}}{2 R}=k / s
$$

Where " $F(R)$ " is the Kubelka-Munk function; "R" represents the absolute value of reflectance, " $\mathrm{k}$ " is the molar absorption coefficient and " $\mathrm{s}$ " is the scattering coefficient. The band gap energies of the $\mathrm{MnFe}_{2} \mathrm{O}_{4}$ NPs was derived by plotting the square of the KubelkaMunk function F (R)2 vs. energy in eV (electron volts).

\section{Preparation of folic acid conjugated DOX-loaded BSA NPs (FA- DOX-BSA-MnFe ${ }_{2} \mathrm{O}_{4} \mathrm{NPs}$ )}

DOX-loaded BSA NPs were prepared by desolvation process followed by cross-linking with glutaraldehyde. The resulting NPs were further loaded with folic acid for targeted drug delivery as reported previously [10], with minor modifications.

\section{Preparation of DOX-loaded BSA decorated $\mathrm{MnFe}_{2} \mathrm{O}_{4} \mathrm{NPs}$}

A $2 \%$ bovine serum albumin solution was prepared by dissolving $0.4 \mathrm{~g}$ BSA in $20 \mathrm{ml}$ distilled water at room temperature. A $20 \mathrm{mg}$ NPs suspension was sonicated in $10 \mathrm{ml}$ distilled water to allow uniform distribution. DOX was then added in an amount two and half times greater than that of NPs used. DOX was first dissolved in $10 \mathrm{ml}$ distilled water and then was added into the NPs BSA solution slowly under constant magnetic stirring. The mixture was then incubated for $1 \mathrm{~h}$. The reaction was allowed to take place at $\mathrm{pH}$ 7.0. Ethanol was added drop-wise at a rate of $1 \mathrm{ml} / \mathrm{min}$ followed by a rest phase of 5 min till the solution became turbid. $25 \%$ glutaraldehyde was added drop-wise into the above solution to cross-link the protein. The solution was then incubated for $2 \mathrm{~h}$ and divided into two parts; one for folate loading and the other to obtain BSA-DOX $\mathrm{MnFe}_{2} \mathrm{O}_{4} \mathrm{NPs}$ after removing organic phase.

\section{Preparation of FA-DOX-BSA conjugates}

Activation of folic acid was carried out by dissolving $0.25 \mathrm{~g}$ of FA into $20 \mathrm{ml}$ of DMSO and the mixture was subjected to sonication for 45 min. The carboxylate group of folic acid was activated by addition of $0.225 \mathrm{~g}$ of $\mathrm{N}$-hydroxysuccinimide and $0.125 \mathrm{~g}$ of 1-ethyl-3-(-3dimethyl-aminopropyl) carbodiimide (EDAC). The reaction was allowed to take place in an inert environment created by argon gas at $28 \pm 2$ for $12 \mathrm{~h}(\mathrm{FA} / \mathrm{NHS} / \mathrm{EDAC}$ molar ratio 2:2:1). After that, we obtained folic-NHS. The activated FA $(1 \mathrm{ml})$ was reacted with $9 \mathrm{ml}$ of BSA-DOX $\mathrm{MnFe}_{2} \mathrm{O}_{4} \mathrm{NPs}$. The mixture was purged with argon under continuous stirring for $4 \mathrm{~h}$. The resulting solution was them centrifuged and subjected to dialysed against nanopure water for the removal of unbound FA.

\section{Encapsulation efficiency (EE)}

The percentage of drug entrapment was calculated according to the procedure reported previously [11], with minor modifications. Initially, the amount of drug present in the clear supernatant after centrifugation was determined $(w)$ by UV/visible spectrophotometer at $477 \mathrm{~nm}$. UV-Vis spectrum of different molar concentrations of DOX (0-0.05 mmol) was recorded and molar absorption coefficient for doxorubicin was determined at $\lambda$ max 477 $\mathrm{nm}$ with the help of standard calibration curve, plotted between absorbance $(477 \mathrm{~nm})$ and concentration $(\mathrm{mM})$. By application of Beer-Lambert law, $A=C \varepsilon L$, the concentration of unbound drug present in the supernatant was obtained followed by calculation of percentage drug entrapment by using the following formula:

$$
\text { Percentage drug entrapment }=\frac{(W-w)}{W} \times 100
$$

Where; "W" is the initial amount of drug added and " $w$ " is the amount of free drug present in the supernatant.

\section{Hemocompatibility assay}

To determine the hemocompatibility of the prepared NPs, hemolysis assay was executed as reported previously [12], with minor modifications. Heparin-stabilized fresh human whole blood from a healthy volunteer donor was collected. Healthy RBCs were isolated from fresh human blood by centrifugation at $2000 \mathrm{rpm}$ for $10 \mathrm{~min}$ and purified by five successive washings with $10 \mathrm{ml} 1 \mathrm{X}$ PBS buffer. Thereafter, the RBCs were diluted 10 times with $1 \mathrm{X}$ PBS buffer. The diluted RBC suspension $(0.1 \mathrm{ml})$ was added to $0.9 \mathrm{ml}$ water (positive control), $0.9 \mathrm{ml}$ PBS (negative control), and $0.9 \mathrm{ml}$ PBS buffer containing NPs, respectively, with a concentration ranging from 30 to $100 \mu \mathrm{g} / \mathrm{ml}$. After a gentle shaking, the mixtures were kept still for $2 \mathrm{~h}$ at room temperature. Then, after centrifugation of the mixture (10000 rpm, $1 \mathrm{~min}$ ), the photos of the mixtures were taken and the absorbance of the supernatants (haemoglobin) was measured in 96-well plate on a microplate reader (AMP platos R496). The hemolysis percentages of the samples were calculated by dividing the difference in absorbance at $541 \mathrm{~nm}$ between the sample and the negative control by the difference in absorbance at $541 \mathrm{~nm}$ between positive and negative controls. 
$\%$ Hemolysis $=\frac{(\text { Abs. of sample }- \text { Abs. of negative control })}{(\text { Abs. of positive control }- \text { Abs. of negative control })}$ $\times 100$

\section{In vitro cytotoxicity}

Prior to screening, the human cervical epithelial malignant carcinoma cell lines (HeLa) were maintained in RPMI-1640 supplemented with $10 \%$ heat inactivated fetal calf serum (Gibco ${ }^{\mathrm{TM}}$, Thermo Fisher Scientific), penicillin $(100 \mathrm{U} / \mathrm{ml})$ and streptomycin $(100 \mu \mathrm{g} / \mathrm{ml})$ at a temperature of $37{ }^{\circ} \mathrm{C}$ in a humidified atmosphere with $5 \% \mathrm{CO}_{2}$. The HeLa cells were used at a concentration of $1.5 \times 10^{5}$ cells $/ \mathrm{ml}$ in this study.

\section{Sulforhodamine B (SRB) assay}

SRB is a dye-based, quick and economic method used to calculate the relative percentage of living cells. The assay was performed according to the procedure reported earlier [13] to analyse the cytotoxic potential of naked NPs in dark on HeLa cells.

Briefly, the pre-seeded HeLa cells (cervical epithelial malignant carcinoma cells; $>90 \%$ viability; $1.2 \times 10^{5}$ cells $/ \mathrm{ml}$ ) were exposed to different concentrations of test NPs $(70,50,30,10 \mu \mathrm{g} / \mathrm{ml})$ in 96 -well culture plates. After $24 \mathrm{~h}$ incubation, cells were fixed by gently adding 50\% pre-chilled trichloroacetic acid (TCA) and incubated at 4 ${ }^{\circ} \mathrm{C}$ for $1 \mathrm{~h}$. The assay plates were rinsed with deionized water at least five times and air dried in order to remove TCA and protein serum. Samples were stained with $0.4 \%$ sulforhodamine B solution for about $30 \mathrm{~min}$ at room temperature and rinsed with $1 \%$ acetic acid to remove unincorporated dye and were air dried. The dye color intensity per well illustrated the number of viable cells it contained. The stained cells were then examined under an inverted microscope (Olympus optical co microscope, Japan).

Mitochondrial function: cell survival and proliferation assay (MTT assay)

MTT [3-(4, 5-dimethylthiazol-2-yl)-2, 5-diphenyltetrazolium bromide] assay was used to investigate mitochondrial function described previously [14] with some modifications. Photocatalytic cytotoxicity evaluation of naked $\mathrm{MnFe}_{2} \mathrm{O}_{4}$ NPs alone and in presence of fixed concentration of doxorubicin was evaluated by subjection to this assay. The same assay was also carried out to determine the potential anticancer activity of BSA-DOX and FA-BSA-DOX conjugated NPs respectively, with and without sunlight exposure, stated as follows.

Pre-seeded HeLa cells (cervical epithelial malignant carcinoma cells; $>90 \%$ viability; $1.2 \times 10^{5}$ cells $/ \mathrm{ml}$ ) cells were incubated with $\mathrm{MnFe}_{2} \mathrm{O}_{4}$
NPs, BSA-DOX and FA-BSA-DOX conjugated $\mathrm{MnFe}_{2} \mathrm{O}_{4} \mathrm{NPs}$ for $4 \mathrm{~h}$ in complete darkness. The concentration of doxorubicin was kept similar $(500 \mathrm{nM})$ while being treated alone and in conjugation with nanoparticles. The cells were then exposed to sunlight to determine any difference in NPs activity as a result of photodynamic effect. As controls, untreated cultures (NTC) and the non-cellular background samples i.e., media only and NPs samples containing MTT and acidified $10 \%$ SDS solution were also included in the experiment.

Afterwards, MTT solution $(0.5 \mathrm{mg} / \mathrm{ml})$ was added to the wells and the samples were incubated for $3 \mathrm{~h}$ at $37^{\circ} \mathrm{C}$. The resulting formazan product was dissolved by adding an equal amount of acidified 10\% SDS and further incubated overnight at $37^{\circ} \mathrm{C}$ Absorbance was measured at 565 $\mathrm{nm}$ by using a microplate reader (AMP Platos R-496). The non-cellular background was subtracted from the respective samples and percent viability was measured relative to the NTC samples. Percentage various viability curves were forthwith generated. The experiment was performed with triplicates for each sample. The cytotoxicity was calculated as percent viability relative to the unexposed samples present on each plate by using the following formula:

$$
\text { Perecntage of live cells }=\frac{(\text { Abs. sample }- \text { Abs. drug control })}{(\text { Abs. unexposed }- \text { Abs. blank })} \times 100
$$

\section{Statistical analysis}

The results were statistically analyzed using t-test (unpaired) with the help of GraphPad Prism (version 6), and P-value of $<0.05$ was considered as significant.

\section{RESULTS}

Hydrophilic $\mathrm{MnFe}_{2} \mathrm{O}_{4}$ NPs prepared by thermal decomposition method were characterized for identification, mean particle size, shape, optical properties, and bandgap.

\section{Characterization of $\mathrm{MnFe}_{2} \mathrm{O}_{4} \mathrm{NPs}$}

The optical absorption spectra of NPs were measured by UV/Vis spectrophotometer (Perkin Elmer UV/Vis-lambda 25) in liquid cuvette configuration. Absorption spectra were taken at room temperature over the range of 250 to $800 \mathrm{~nm}$. Fig. 1A showed characteristic absorption peak at $315 \mathrm{~nm}$ which indicate the presence of synthesized metal oxide NPs. Fig. 1B presents the XRD patterns of $\mathrm{MnFe}_{2} \mathrm{O}_{4} \mathrm{NPs}$ prepared by thermal decomposition method. The pattern showed the reflection planes (220), (311), (400), (422), (511), (440) which confirm the presence of a single phase $\mathrm{MnFe}_{2} \mathrm{O}_{4}$ with a face-centered spherical structure.
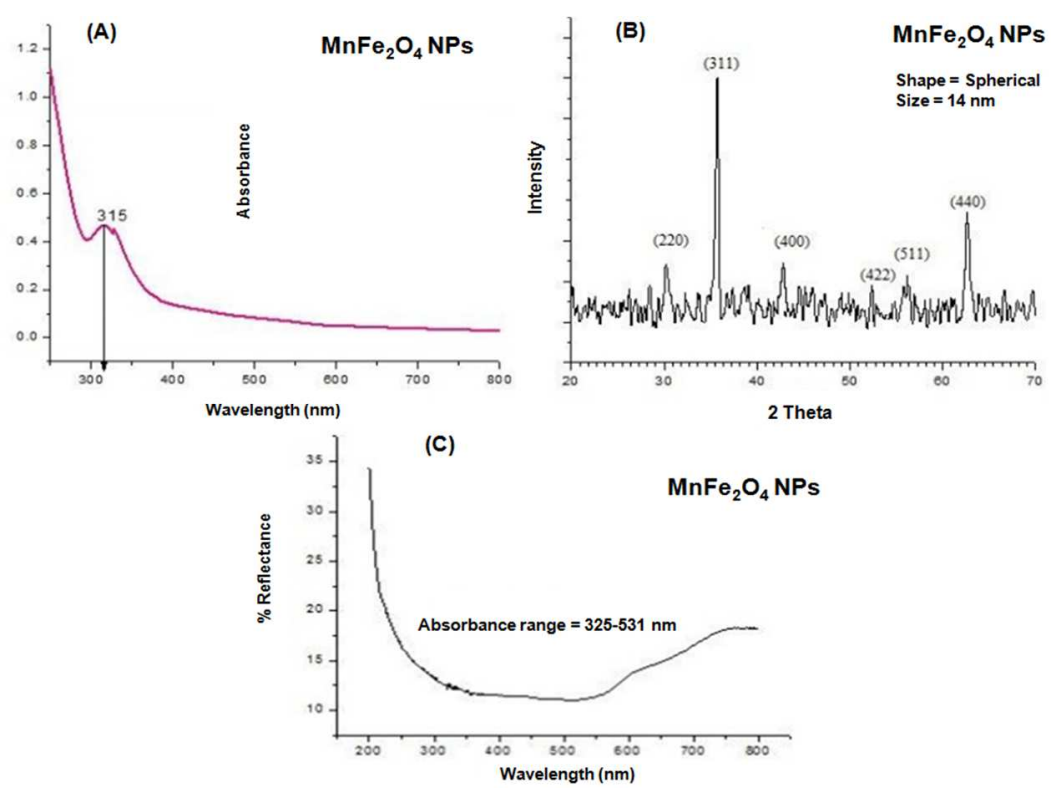

Fig. 1: (A) UV-Vis absorbance spectra of $\mathrm{MnFe}_{2} \mathrm{O}_{4} \mathrm{NP}$. The characteristic absorption peak at $315 \mathrm{~nm}$ demonstrates the presence of synthesized metal oxide NPs. (B) XRD pattern of $\mathrm{MnFe}_{2} \mathrm{O}_{4} \mathrm{NP}$. The average particle size was determined to be $14.2 \mathrm{~nm}$ from full width at half maximum with a spherical shape. (C) Diffused reflectance spectra of $\mathrm{MnFe}_{2} \mathrm{O}_{4} \mathrm{NP}$ 
Also, the main diffraction peaks indexed to $\mathrm{MnFe}_{2} \mathrm{O}_{4}$ (cubical) appeared at $2 \theta=$ $30^{\circ}, 35.4^{\circ}, 43.9^{\circ}, 53,56.3$ and $63.2^{\circ}$, whereas, no other impurity peak was detected in XRD pattern. The average particle size was estimated to be 14.2 $\mathrm{nm}$ from the full width at half maximum (FWHM) using the well-known Debye-Scherrer equation $(D=0.9 \lambda / \beta \cos \theta)$. Further analysis of the prepared NPs revealed the reflectance spectra of $\mathrm{MnFe}_{2} \mathrm{O}_{4}$ NPs taken at room temperature in the range of 200-800 $\mathrm{nm}$. The diffuse reflectance spectrum of synthesized sample shows characteristic absorption in the range of 325-531 nm (fig. 1C).

On the other hand, fig. 2 presents the band gap energy of $\mathrm{MnFe}_{2} \mathrm{O}_{4} \mathrm{NPs}$ through Kubelka-Munk function by treating their diffuse reflectance spectra. The band gap energies of the $\mathrm{MnFe}_{2} \mathrm{O}_{4} \mathrm{NPs}$ has been derived by plotting the square of the Kubelka-Munk function $F(R) 2$ vs. energy in $\mathrm{eV}$ (electron volts). The direct band gap energy of $\mathrm{MnFe}_{2} \mathrm{O}_{4} \mathrm{NPs}$ was estimated from the intercept of tangents to the plots. This band gap energy thus came out to be $1.4 \mathrm{eV}$.

\section{Hemocompatibility analysis}

This present study was aimed to assess the hemocompatibility of the prepared metal oxide NPs with blood. In this study, the pelleted red blood cells (RBCs) were treated with different concentrations of metal oxide NPs $(30,50,70$ and $100 \mu \mathrm{g} / \mathrm{ml})$ and were compared with the negative control (RBCs treated with PBS) and positive control (RBCs treated with double distilled water). Resulting data suggested that there was no sign of hemolysis in all the treatment groups in contrast to the positive control groups (fig. 3). These findings suggested that metal oxide NPs were hemocompatible even at higher concentrations and therefore are appropriate for further in vitro analysis.

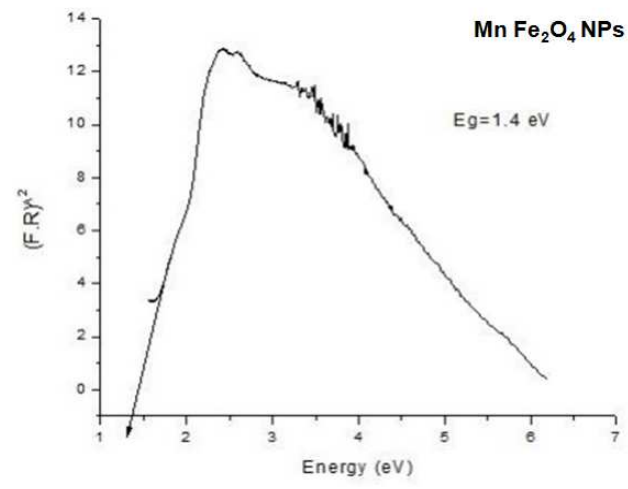

Fig. 2: Band gap energy of $\mathrm{MnFe}_{2} \mathrm{O}_{4}$ NPs through Kubelka-Munk function by treating their diffuse reflectance spectra. A bandgap of 1.4 $\mathrm{eV}$ highlights that the NPs can be excited through infrared radiation (a)

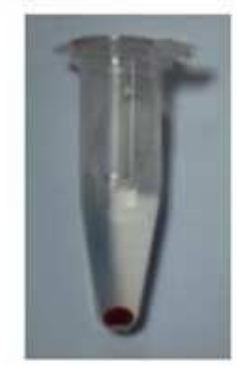

(b)

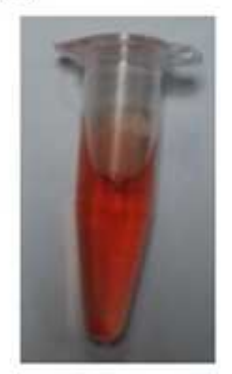

(c)

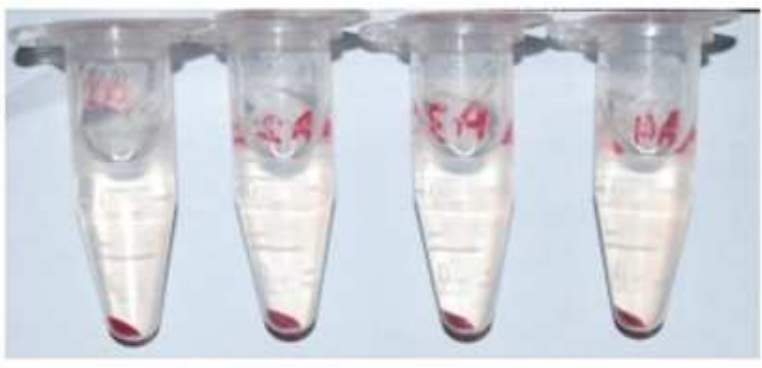

$30 \mathrm{ug} / \mathrm{mL} \quad 50 \mathrm{ug} / \mathrm{mL} \quad 70 \mathrm{ug} / \mathrm{mL} \quad 100 \mathrm{ug} / \mathrm{mL}$

Fig. 3: Hemocompatibility of NPs: (a) treatment of RBCs with PBS (negative control), (b) treatment of RBCs with double distilled water (positive control), and (c) treatment of RBCs with different concentrations of $\mathrm{MnFe}_{2} \mathrm{O}_{4}$ NPs. Results showed no hemolysis and suggested that NPs are hemocompatible at various concentrations

Cytotoxicity studies

\section{Microscopic analysis (SRB assay)}

In this study, the treated cells were evaluated under an inverted microscope (Olympus optical co microscope, Japan) to assess any sort of morphological changes or death of cells.

The resulting data showed greater cell viability $(78 \%)$ in the cell culture treated with $70 \mu \mathrm{g} / \mathrm{ml}$ (fig. 4). These findings suggested that the naked particles themselves were non-cytotoxic to the cells in dark (fig. 4).

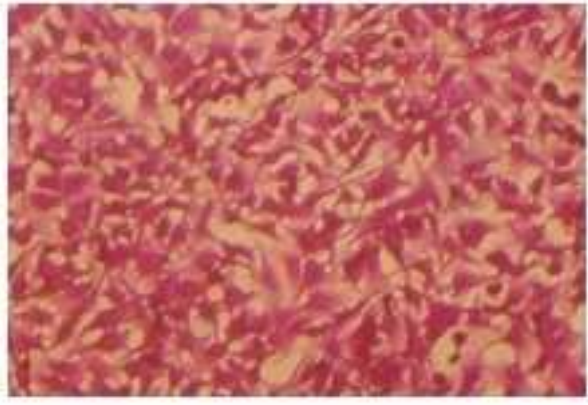

(a) NTC

(Negative control)

$100 \%$ cell viability

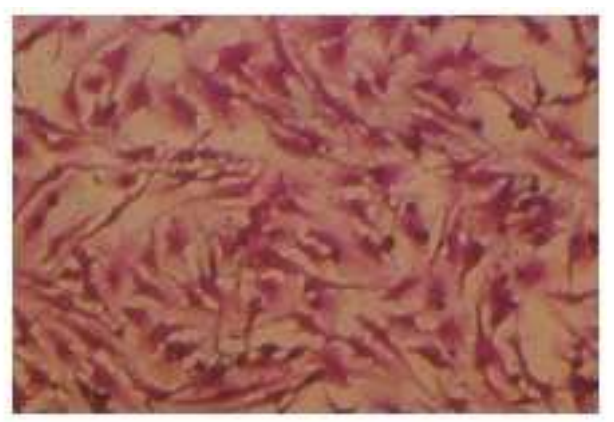

(b) $70 \mathrm{ug} / \mathrm{ml}$

\section{(Drug effect)}

$78 \%$ cell viability

Fig. 4: Cell viability observed under inverted microscope: (a) Cells without NPs/drug treatment and (b) Cells treated with $70 \mu \mathrm{g} / \mathrm{ml}$ of NPs dispersion 


\section{Cell viability (MTT assay)}

MTT assay was carried out to evaluate the photo-mediated cytotoxicity of naked $\mathrm{MnFe}_{2} \mathrm{O}_{4} \mathrm{NPs}$ alone and in combination with fixed concentration of DOX. The results indicated that the naked NPs did not exhibit potential anti-cancer (cytotoxic) activity in dark, neither alone nor any combinational anticancer effect was observed in conjugation with an IC50 value of DOX. In comparison, not only did naked NPs exhibit decrease in cell viability in case of sunlight exposed samples, but also combinational effect was observed in association with IC50 DOX, increasing with an increase in the concentration of NPs in an order $5<10<30<50<70 \mu \mathrm{g} / \mathrm{ml}$ (fig. $5 \mathrm{~A}$ and $\mathrm{B}$ ). Fig. 5B represents the cell viability curve plotted between $\%$ viability versus concentration $(\mu \mathrm{g} / \mathrm{ml})$.

(A)

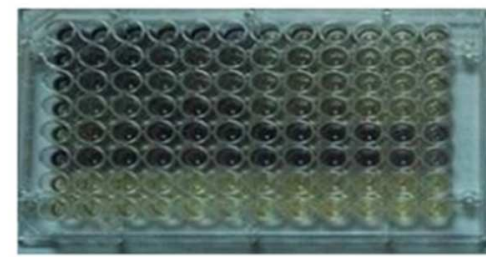

Unexposed plate

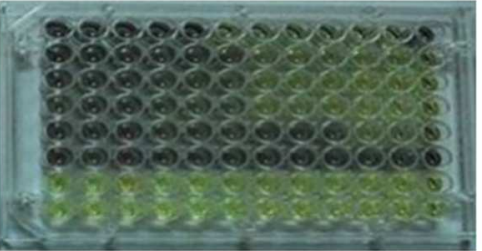

Sunlight exposed plate

(B)

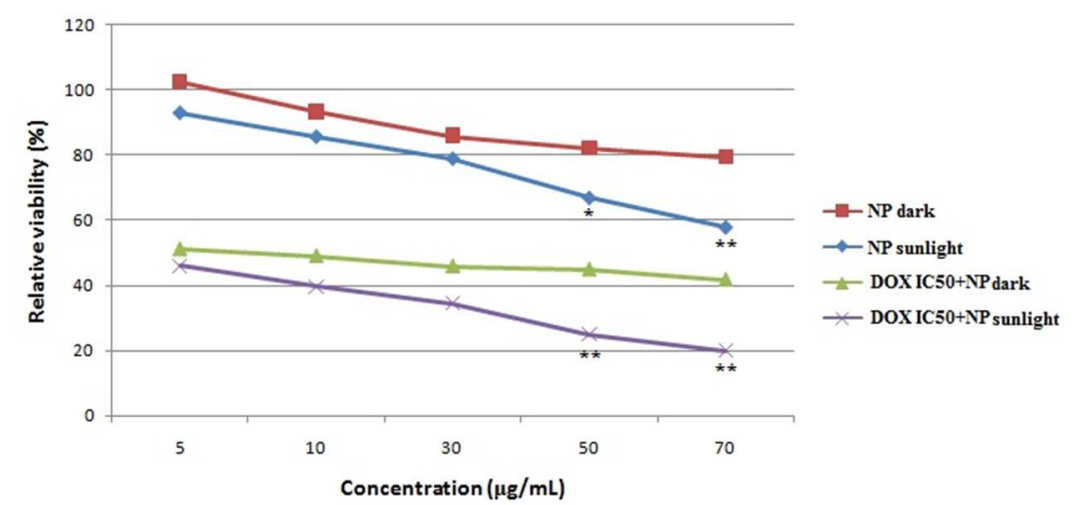

Fig. 5: (A) Photo-mediated cytotoxicity following sunlight exposure. HeLa cells were treated with different concentrations $(5,10,30,50$, $70 \mu \mathrm{g} / \mathrm{ml}$ ) of NPs and fixed concentration of doxorubicin (DOX) $25 \mu \mathrm{M}$ (IC50) in dark and sunlight, (B) Cell viability curve plotted between $\%$ viability and concentration $(\mathrm{ug} / \mathrm{ml})$ in dark and sunlight. Significant photo-mediated cytotoxicity was observed in case of NPs at concentrations $5,10,30,50,70 \mu \mathrm{g} / \mathrm{ml}$ after sunlight exposure

\section{Entrapment efficiency (EE)}

UV-Vis spectrum of different molar concentrations of DOX (0-0.05 mmol) was recorded and molar absorption coefficient for doxorubicin was determined which was $4 \mathrm{mmol}^{-1} \mathrm{~cm}^{-1}$ at $\lambda \max 477$ $\mathrm{nm}$, with the help of standard calibration curve plotted at $477 \mathrm{~nm}$.

By application of Beer-Lambert law, $A=C \varepsilon L$, the concentration of unbound drug present in supernatant came out to be $2.47 \mathrm{mg}$, out of the total $50 \mathrm{mg}$ drug initially added. Finally, upon the application of the formula $(\% \mathrm{EE})$, the percentage of drug entrapment was calculated to be $95.06 \%$.

\section{Photo-mediated cytotoxicity}

The photo-mediated cytotoxic activity of both the BSA-DOX conjugated and FA-BSA-DOX conjugated $\mathrm{MnFe}_{2} \mathrm{O}_{4}$ NPs were analyzed by subjecting them to MTT assay on HeLa cell line. Upon treatment of the respective particles on the cells, they were exposed to sunlight for $0,10,20$ and $30 \mathrm{~min}$, respectively. It was observed that the cell viability decreased exponentially with the passage of time, with FA-BSA-DOX loaded NPs showing greater activity in comparison to BSA-DOX loaded NPs (fig. 6).

\section{DISCUSSION}

Super paramagnetic iron oxide NPs extend attractive possibilities for the amelioration of site-specific drug delivery, on account of their transportation to targeted areas by an external magnetic field.
Furthermore, they have also been used for the enhancement of magnetic resonance imaging contrast in cancer detection [6], which could be coupled with localized hyperthermia treatments in the socalled theranostic approach [15].

One such reported superparamagnetic NPs, $\mathrm{MnFe}_{2} \mathrm{O}_{4}$, is a potential candidate contrast agent for magnetic resonance imaging, because of a high magnetisation due to large magnetic spin [7]. The aim of the present study was to develop $\mathrm{MnFe}_{2} \mathrm{O}_{4}$ NPs for targeted drug delivery in cancer therapy, and also determining their activity as potential photo-oxidation-mediated cytotoxic agents.

The hydrophobic monodispersed $\mathrm{MnFe}_{2} \mathrm{O}_{4}$ NPs were prepared by thermal decomposition method using oleic acid as the surfactant and reducing agent. Oleic acid binds to the NPs through the carboxyl end, with aliphatic chains exuding out from the surface, rendering the final product hydrophobic and suspended only in non-polar solvents [16]. To overcome these limitations, citric acid was conjugated on the surface of the $\mathrm{MnFe}_{2} \mathrm{O}_{4}$ NPs [17] by direct ligand exchange reaction as reported previously [18]. Citric acid displaces the hydrophobic oleic acid present on the surface of NPs, thus not only adding to stability by preventing further agglomeration by imparting a surface charge on separate NPs, but also rendering them hydrophilic, consequently helping them to transform into biocompatible NPs. Furthermore, the NPs distribution in aqueous solution enhances the production of ROS (reactive oxygen species) such as singlet oxygen, hydrogen peroxide, hydroxyl radical and superoxides [19]. 


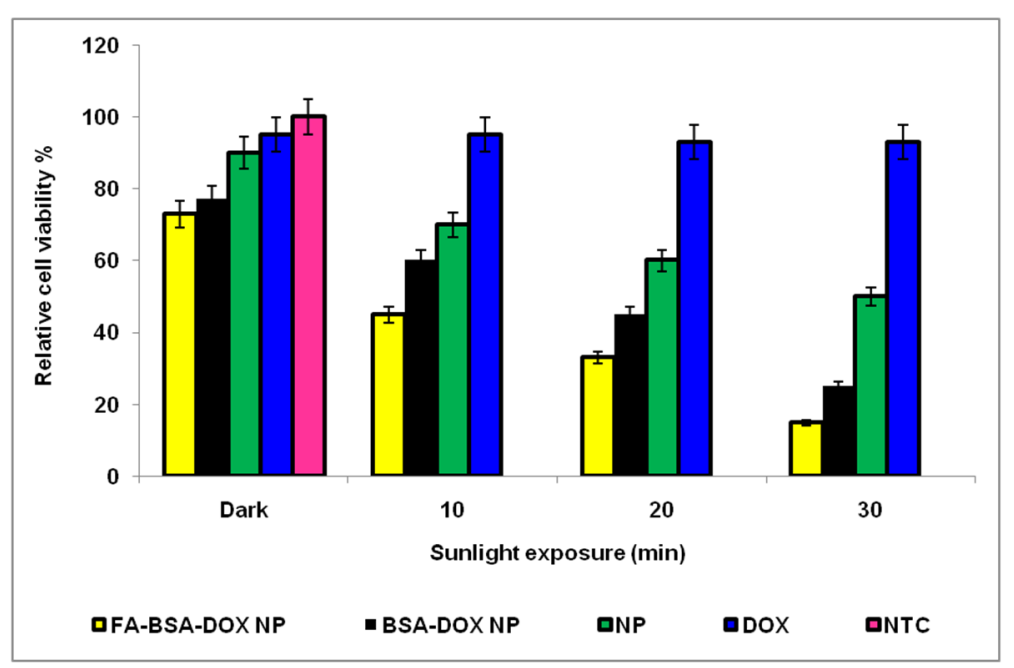

Fig. 6: Relative cell viability studies as a function of sunlight exposure time. The concentration of doxorubicin (DOX) was kept constant $(500 \mathrm{nM})$ while being treated alone and in conjugation with nanoparticles. Data showed that sunlight exposure did not bear any effect on the viability of NTC nor on DOX-treated cells; however, a significant decrease in cell viability was observed in cells treated with folic acidconjugated doxorubicin-loaded bovine serum albumin NP (FA-BSA-DOX NP) and in the case of doxorubicin-loaded bovine serum albumin NP (BSA-DOX NPs). Data is presented as mean \pm S. D $(n=3)$

The characterization results of the monodispersed hydrophilic NPs produced showed that the particles are spherical in shape with a size of approx. $14.2 \mathrm{~nm}$, and a band gap of $1.4 \mathrm{eV}$. The band gap generally refers to the energy difference (in electron volts) between the top of the valence band and the bottom of the conduction band in insulators and semiconductors. This energy difference is the same as the energy required to free a valence shell electron from its orbit about the nucleus to become a mobile charge carrier. A bandgap of $1.4 \mathrm{eV}$ thus corresponds to the fact that the particles need to be subjected to Infrared radiation for the release of the outermost electron [20], thus configuring them into an excited state able to interact with neutral oxygen species in the surroundings to form reactive oxygen species.

As a criterion for analysis of hemocompatibility of test sample, the American society of testing and materials E2524-08 standard states that hemolysis rate greater than $5 \%$ shows that the test sample causes damage to RBCs [21]. However, it was shown that, even at $100 \mu \mathrm{g} / \mathrm{ml}$, the particles did not exhibit hemolysis which demonstrated that these NPs are fit for injection into the blood stream. The zero-hemolysis effect shows that the NPs do not produce enough oxidative stress to cause RBC destruction nor do they cause mechanical damage to the components of the cell membrane's lipid bilayer to elicit any hemolytic effect [22], thus making them suitable for use as a vehicle in drug delivery.

The NPs were screened for cytotoxicity against HeLa cell line through SRB assay. Based upon the data published previously [23], NP treatments are shown to exhibit 'no effect' when the measured viability is greater than $50 \%$, a 'moderate effect' when the viability ranges between 50 and $25 \%$, and a 'strong effect' when viability below $25 \%$ is observed. Based upon the said standards, it was visually observed that the particles were non-cytotoxic even at $70 \mu \mathrm{g} / \mathrm{ml}$ concentration, under dark conditions. The reason, as previously discussed, is that for the excitation of NPs with a band gap of $1.4 \mathrm{eV}$, external radiation in the Infrared region needs to be exposed upon the NPs. This energy can be obtained from direct sunlight exposure, as it is around 52 to 55 percent infrared [24]. Thus, for determination of potential photo-oxidation-mediated cytotoxic activity against cancer cells, the NPs after treatment, alone and in combination with a fixed concentration of DOX (IC50), demonstrated enhanced cytotoxic effect upon a brief sunlight exposure, in contrast to the particles treated under dark conditions. One of the probable reasons for this enhanced cytotoxicity comes from the fact that semiconductor NPs, in this case, MnFe204, catalytically generate ROS in response to photoirradiation [25]. Following excitation with photons of energies greater than or equal to their band gap, these NPs undergo a charge separation in their crystal lattice where electrons in the valence band localize to the conduction band, with positive holes being left behind. This leads to the generation of hydroxyl radicals $(\cdot \mathrm{OH})$, hydrogen peroxide $\left(\mathrm{H}_{2} \mathrm{O}_{2}\right)$ and superoxide anions $\left(\mathrm{O}^{2-}\right)$, all of which are cytotoxic oxidizing species, collectively called reactive oxygen species. When the intensity of these ROS exceeds the anti-oxidation capacity of the cancer cells, they cause cell membrane damage, permeability changes and DNA damage by activation of p53 pathway, leading to apoptosis of cancer cell [26].

The observed hemocompatibility and photo-oxidation mediated cytotoxicity favoured the proceeding of the next step i.e. generation of targeted folic acid-conjugated, DOX-loaded magnetic $\mathrm{MnFe}_{2} \mathrm{O}_{4} \mathrm{BSA}$ NPs (FA-BSA-DOX $\mathrm{MnFe}_{2} \mathrm{O}_{4} \mathrm{NPs}$ ) that lower the side effects and improve the therapeutic effect of anticancer drugs when combined with photo-oxidation mediated cytotoxicity and targeting therapy.

BSA is an attractive molecular carrier and an ideal carrier for NPs preparation [27]. Additionally, it is used to enhance plasma duration of the folate-BSA molecules because macrophages do not capture BSA in the liver, nor excrete it through kidney excretion, thus enhancing the probability of contact between the folate-BSA and the folate receptor. Another advantage attributed to the use of BSA as drug carrier is that it releases an insignificant quantity, of DOX at physiological pH (7.4) of blood and normal tissues. Instead, an acidic environment is needed for the release of drug from BSA-conjugated NPs. As the internal pH of tumor tissues and cancer cells is slightly acidic, the NPs would release the drug favourably inside the cancer tissues thus promoting cancer cell specific drug release, leaving the normal cells and tissues unaffected [28]. DOX was used as the anticancer drug of choice because of its widespread use in chemotherapy and well reported adverse effects, such as irreversible cardiomyopathy and subsequent congestive heart failure, due to lack of specificity [29].

In the receptor-mediated targeted delivery, folic acid has been a promising star. The rationale of using this folic acid as a targeting ligand is based on the data that folic acid has (1) a small size, which results in advantageous pharmacokinetics of the folate derivatives and decreased chance of immunogenicity thereby favoring repeated administration; (2) ease of access and low cost; (3) simple and defined conjugation chemistry; (4) high receptor affinity; (5) the receptor/ligand complex is internalized via endocytosis, thus permitting the cytosolic delivery of therapeutic agents, and (6) 100 times greater expression of folate receptors on cancer cells in comparison to normal cells. Therefore, folate-based targeting systems show great potential for future clinical diagnostic and therapeutic applications [30].

DOX-BSA $\mathrm{MnFe}_{2} \mathrm{O}_{4}$ NPs were prepared using a desolvation crosslinking method, with ethanol as the desolvating agent (acts as 
an anti-solvent for BSA in order to decrease the solubility in water and promoting NPs formation by precipitation) and $25 \%$ glutaraldehyde as the cross-linking agent. With the help of UV-vis spectroscopy, the drug encapsulation efficiency was calculated to be $95.06 \%$. Upon activation of folic acid in the form of NHS-folate, FABSA-DOX $\mathrm{MnFe}_{2} \mathrm{O}_{4}$ NPs were prepared by combining BSA-DOX $\mathrm{MnFe}_{2} \mathrm{O}_{4}$ NPs with folic acid through amino groups. The final product was then dialyzed against nanopure water to remove unbound folic acid. To assess cytotoxic activity of the BSA-DOX and FA-BSA-DOX conjugated $\mathrm{MnFe}_{2} \mathrm{O}_{4}$ NPs in dark and in sunlight (for additional photo-oxidation mediated cytotoxicity), they were subjected to MTT assay at a fixed concentration of DOX (500nM). The results showed that the respective drug and folic acid NP conjugates exhibited an increasing trend in cytotoxicity with the passage of time, with FA-BSA-DOX conjugated $\mathrm{MnFe}_{2} \mathrm{O}_{4}$ NPs exhibiting a comparatively greater activity in comparison to BSADOX conjugated NPs, owing to the probable folate-receptormediated endocytosis and internalisation.

\section{CONCLUSION}

The present study was executed to investigate the photosensitizing and anticancer efficacy of the manganese ferrite NPs against human cervical carcinoma cell line. The resulting data revealed that the prepared NPs exhibited a smaller particle size, spherical morphology, and higher entrapment efficiency. The metal oxide NPs showed extended photomediated cytotoxicity upon exposure to sunlight which increased exponentially when their concentration was increased. Additionally, FABSA-DOX conjugated NPs exhibited relatively higher cytotoxicity compared to the BSA-DOX conjugated NPs. The demonstrated pattern in cytotoxicity of human cervical carcinoma cells (HeLa) evidenced a significant potential of these NPs delivery system in the treatment of malignant cervical carcinoma.

\section{ACKNOWLEDGMENT}

Authors would also like to acknowledge the department of Biochemistry, Quaid-i-Azam University, Institute of Biomedical and Genetic Engineering and National Centre for Physics for providing resources to accomplish the present research project.

\section{AUTHOR CONTRIBUTION}

Synthesis of drug loaded nanoparticles, determination of photomediated cytotoxicity and cell viability studies were performed by Mr. Muhammad Hassan Safdar, under the supervision of Dr. Mariam Anees. The hemocompatibility studies were performed by Ms. Humna Hasan. Dr. Zahid Hussan analyzed the resulting data and proof-read the manuscript.

\section{CONFLICT OF INTERESTS}

Declared none

\section{REFERENCES}

1. Wicki A, Witzigmann D, Balasubramanian V, Huwyler J. Nanomedicine in cancer therapy: challenges, opportunities, and clinical applications. J Controlled Release 2015;200:138-57.

2. Vijay M, Anu Y. Anticancer activity of camellia Sinensis mediated copper nanoparticles against HT-29, MCF-7, and MOLT-4 human cancer cell lines. Asian J Pharm Clin Res 2017;10:82-8.

3. Lv R, Yang P, He F. A yolk-like multifunctional platform for multimodal imaging and synergistic therapy triggered by a single near-infrared light. ACS Nano 2015;9:1630-47.

4. Fang W, Yang J, Gong J, Zheng N. Photo-and pH-triggered release of anticancer drugs from mesoporous silica-coated Pd/Ag nanoparticles. Adv Funct Mater 2011;22:842-8.

5. Bano S, Nazir S, Munir S, Al Ajmi MF, Afzal M, Mazhar K. "Smart" nickel oxide based core-shell nanoparticles for combined chemo and photodynamic cancer therapy. Int J Nanomed 2016;12:3159-66.

6. Pankhurst QA, Thanh SQ, Jones SK, Dobson J. Progress in applications of magnetic nanoparticles in biomedicine. J Phys D Appl Phys 2009;42:1088-109.
7. Lee JH, Huh YM, Jun YW, Seo JW, Jang JT, Song HT, et al. Artificially engineered magnetic nanoparticles for ultrasensitive molecular imaging. Nat Med 2007;13:95-9.

8. Lattuada M, Hatton TA. Functionalization of monodisperse magnetic nanoparticles. Langmuir 2007;23:2158-68.

9. Sanchez R, Sarry JE, Murphy K, Perry R, Secreto A, Keefer C, et al. Human acute myelogenous leukemia stem cells are rare and heterogeneous when assayed in NOD/SCID/IL2R $\gamma c-d e f i c i e n t$ mice. J Clin Invest 2011;121:384-95.

10. Rupa Y, Makiful P, Haque R, Sireesha D, Vasudha B, Harshini S. Method development and validation for the simultaneous estimation of doxycycline and ornidazole in bulk and pharmaceutical dosage form by using the RP-HPLC method. Int J Med Nanotechnol: Medtechnano 2014;1:179-85.

11. Bellare J, Banerjee R, Das S. Aspirin loaded albumin nanoparticles by coacervation: implications in drug delivery. Trends Biochem 2005;18:203-11.

12. Hu H, Zhou H, Du J, Wang Z, Ann L, Yang H, et al. Biocompatible hollow silica microspheres as novel ultrasound contrast agents for in vivo imaging. J Mater Chem 2011;21:6576-83.

13. Skehan P, Storeng R, Scudiero D, Monks A, McMahon J, Vistica $D$, et al. New colorimetric cytotoxicity assay for anticancer-drug screening. J Natl Cancer Inst 1990;82:1107-12.

14. Mosmann T. Rapid colorimetric assay for cellular growth and survival: application to proliferation and cytotoxicity assays. J Immunol Methods 1983;65:55-63.

15. Yang H, Zhang C, Shi X, Hu H, Du X, Fang Y, et al. Water-soluble superparamagnetic manganese ferrite nanoparticles for magnetic resonance imaging. Biomaterials 2012;31:3667-73.

16. Goodarzi AA, Jonnalagadda JC, Pauline D, David Y, Ruiqiong Y, Greg BG, et al. Autophosphorylation of ataxia-telangiectasia mutated is regulated by protein phosphatase $2 \mathrm{~A}$. EMBO J 2004;23:4451-61.

17. Cheraghipour E, Javadpour S, Mehdizadeh AR. Citrate-capped superparamagnetic iron oxide nanoparticles used for hyperthermia therapy. J Biomed Sci Eng 2012;5:715-9.

18. Lattuada M, Hatton TA. Functionalization of monodisperse magnetic nanoparticles. Langmuir 2007;23:2158-68.

19. Arooj S, Nazir S, Nadhman A, Ahmad N, Muhammad B, Ahmad I, et al. Novel $\mathrm{ZnO}$ : Ag nanocomposites induce significant oxidative stress in human fibroblast malignant melanoma (Ht144) cells. Beilstein J Nanotechnol 2015;26:570-82.

20. Koyama T, Ito $\mathrm{Y}$, Yoshida $\mathrm{K}$, Tsuji M, Ago H, Kishida H, et al. Near-infrared photoluminescence in the femtosecond time region in monolayer graphene on $\mathrm{SiO}_{2}$. ACS Nano 2013;7:233543.

21. Choi J, Reipa V, Hitchins VM, Goering PL, Malinauskas RA. Physicochemical characterization and in vitro hemolysis evaluation of silver nanoparticles. Toxicol Sci 2011;123:13343.

22. Mocan T. Hemolysis as an expression of nanoparticles-induced cytotoxicity in red blood cells. BMBN 2013;1:2330-45.

23. Arooj F, Ahmad N, Muhammad N. Pilot scale application of ozone to bleach raw cotton fabric using various additives. Ozone Sci Eng 2014;92:111-4.

24. Zamfirescu R, Tiberiu CS, Iulian G, Monica P, Alexandru S. Refining climate change projections for organisms with low dispersal abilities: a case study of the caspian whipsnake. PLoS One 2014;13:234-42.

25. Chen X, Mao SS. Titanium dioxide nanomaterials: synthesis, properties, modifications, and applications. Chem Rev 2007;107:2891-959.

26. Ozben T. Oxidative stress and apoptosis: Impact on cancer therapy. J Pharm Sci 2007;96:2181-96.

27. Namasivayam SKR, Robin ATG. Preparation, optimization and characterization of biocompatible nano albumin-ofloxacin (bsanp-of) conjugate and evaluation of control release, antibacterial activity against a clinical isolate of pseudomonas aeruginosa. Asian J Pharm Clin Res 2013;6:235-9.

28. Rahimnejad MM, Jahanshahi M, Najafpour GD. Production of biological nanoparticles from bovine serum albumin for drug delivery. Afr J Biotechnol 2006;5:134-52. 
29. Xiaolan $\mathrm{Q}$, Chang $\mathrm{Y}$, Jing $\mathrm{Z}$, Nan D, Yao L, Lei H. In vitro evaluation of a folate-bovine serum albumin-doxorubicin conjugate. J Drug Target 2010;18:351-61.

30. Yang R, Yan L, Feng QM, Meng FL, Dang L, Sha T. Preparation of folic acid-conjugated, doxorubicin-loaded, magnetic bovine serum albumin nanospheres and their antitumor effects in vitro and in vivo. Int J Nanomed 2014;9:4231-43.

\section{How to cite this article}

- Muhammad Hassan Safdar, Humna Hasan, Mariam Anees, Zahid Hussain. Folic acid-conjugated doxorubicin-loaded photosensitizing manganese ferrite nanoparticles: synthesis, characterization and anticancer activity against human cervical carcinoma cell line (hela). Int J Pharm Pharm Sci 2017;9(5):60-67. 